\title{
Development and Integration of Engineering Processes at Oerlikon Aerospace
}

\author{
Claude Y. Laporte, Nicola R. Papiccio \\ Oerlikon Aerospace \\ 225, boul. du Séminaire Sud \\ Saint-Jean-sur-Richelieu \\ (Québec) Canada J3B 8E9
}

\begin{abstract}
In order to reduce cycle time, increase customer satisfaction and lower costs, Oerlikon Aerospace has initiated, in 1992, a project to define and implement software and systems engineering processes. The initiative started by performing a formal assessment of current software engineering practices. An action plan was developed and multi-functional working groups were tasked to define and facilitate the implementation of software processes. A second initiative was started, in 1995, with the objective of defining and implementing a systems engineering process, and integrating to the systems engineering process the software engineering process already in use.
\end{abstract}

\section{Background}

Oerlikon Aerospace is a systems integrator of a complex laser-guided missile air defense system. The system consists of five technology/product families: processing and display, platform system, sensors and effectors, command, control, communication and intelligence, and readiness system (e.g. training, simulators and test). Over 60 systems and software engineers are involved in the development and maintenance of the system.

At Oerlikon Aerospace, the approach, to process engineering was fourfold: first, define a process and bring it under management control; secondly, support the process with methods; thirdly, support the process and methods with appropriate tools; and fourth, train all personnel in the utilization of processes, methods and tools.

\section{Development of a Software Engineering Process}

In fall 1992, recognizing that software engineering was a core competence of Oerlikon Aerospace, the president approved the establishment of a Software Engineering Process Group (SEPG)(Fowler 1990). A budget was also approved for the conduct of a Software Process Assessment (SPA), using the Capability Maturity Model for software (CMM) (Paulk 1993) as a framework, and the development of an action plan.

In spring 1993, a SPA was performed jointly by the SEPG and by independent assessors certified by the Software Engineering Institute (SEI). Strengths and weaknesses were identified and priorities for improvements were recommended.

In the summer and fall 1993 a detailed action plan was prepared by the SEPG. It was decided that working groups would be established to define individual processes under the close coordination of the SEPG. For each process, a process owner, i.e. a person responsible for the implementation and improvement of a process, was identified. The following processes were developed, tested in pilot projects and implemented: software development, software maintenance, software project planning and tracking, software quality assurance, software configuration management, software subcontractor management, documentation management and document inspection (Gilb 1993).

Each process is described at three level of details. To illustrate the work performed, the planning and tracking process is described. At the higher level of details, there are three phases (see figure 1): the 
planning activities during a proposal phase, the project planning phase after contract award, and the project tracking phase. The proposal phase eithetakes the original vision of a potential product and transforms it into a business case or, for a contractual development, the requirements of the request for proposal are analyzed: size, cost and schedule estimates are performed, and a risk analysis is done. For both cases the main outcome of this phase is a go no-go decision. Since, during the contract negotiation phase, it is possible that some requirements (i.e. schedule, software requirements) have been modified, the planning phase after contract award is required to finalize the plans prepared during the proposal phase. During the third phase, project data are collected, analyzed and adjustments to the initial plans are made.

The second level of details of the planning and tracking activities during the proposal phase is illustrated in figure 2 As shown, each step of the process is numbered; also, each step is defined with a verb and a noun. The steps could be used as building blocks and could be linked together according to the needs of the project. It is the responsibility of the project manager to tailor the building blocks. Even though the steps are illustrated as a linear set of steps, feedback to previous steps are allowed. Feedback loops have not been illustrated in order not to clutter the diagrams.

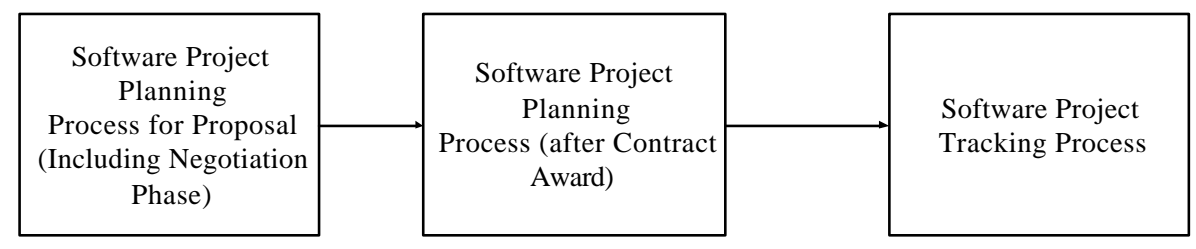

Figure 1: Three Phases of the Project Planning and Tracking Process
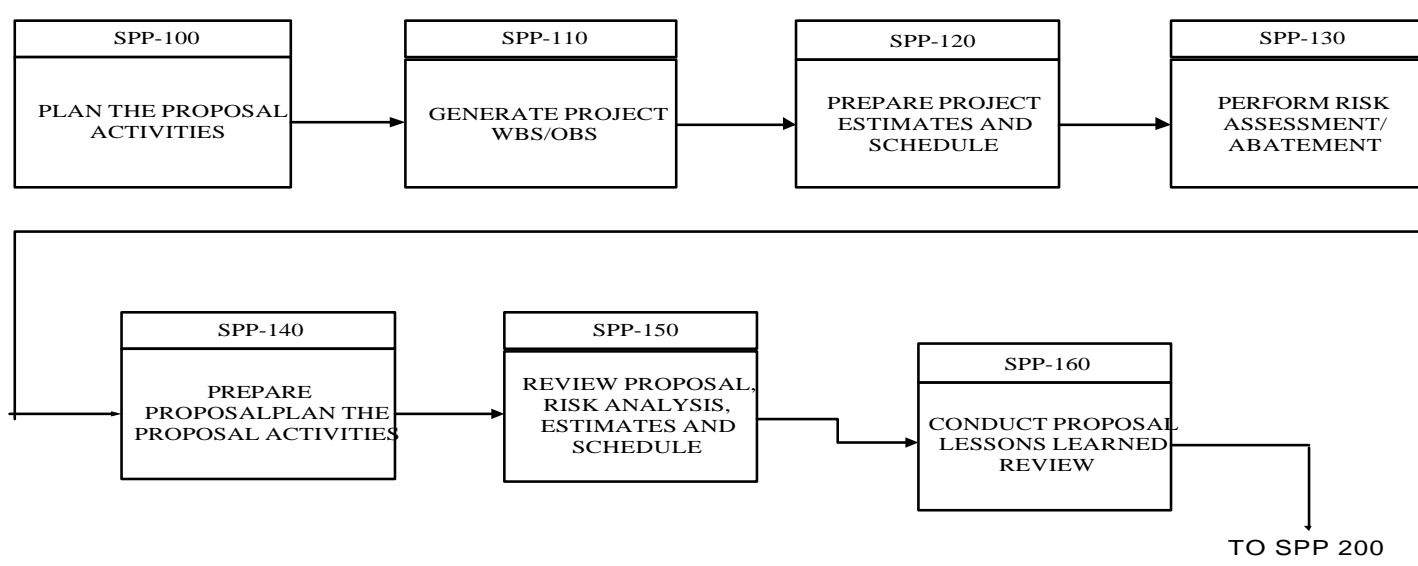

WBS $=$ Work Breakdown Structure

OBS $=$ Organization Breakdown Structure

Figure 2: Software Planning Process for Proposal

Figure 3 illustrates the third level of details. The figure shows the ETVX diagram of step SPP-120. Since the diagram cannot contain all the information for a particular step, diagrams are complemented by text. 


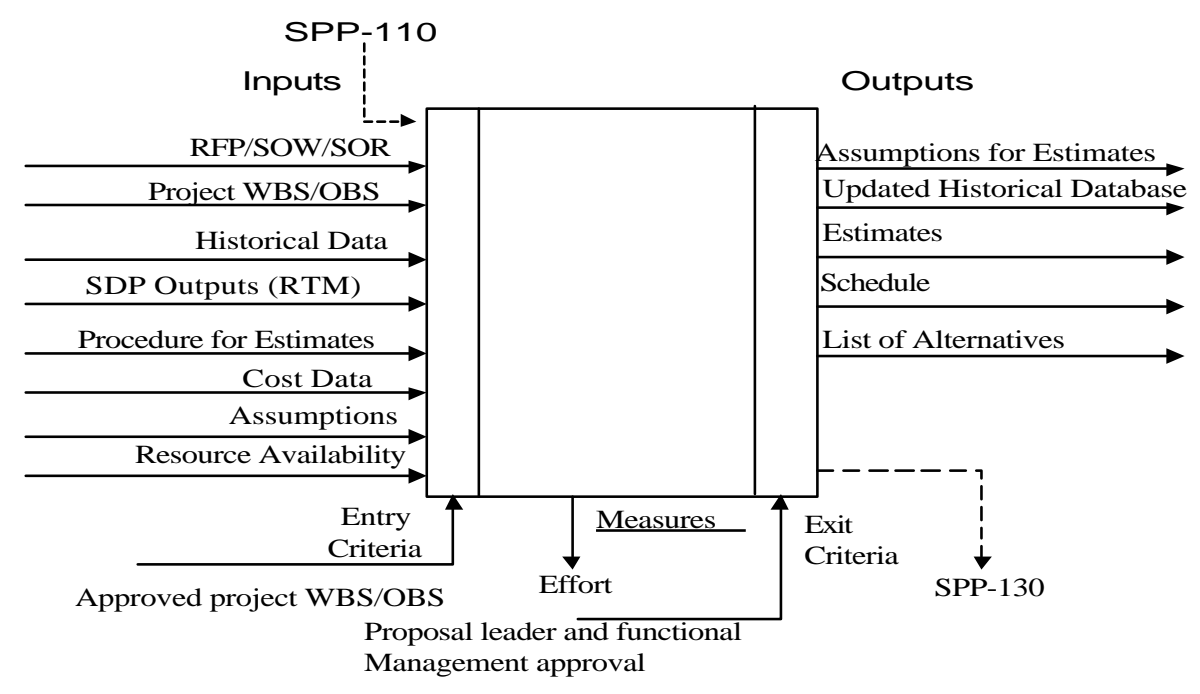

Figure 3: ETVX Diagram of Step SPP-120

A reverse engineering process is presently being defined. It will draw on the experiences based on the process developed under the STARS program (Software Technology for Adaptable, Reliable Systems) (STARS 1995). The reverse engineering process will have the following three major steps: first, define project step which will include 1) define objectives, 2) identify baseline, 3) define reengineering project plan; a second major step to reverse engineer the software system, and a third major step to "forward" engineer the software.

A second formal software process assessment was conducted in February 1997. Oerlikon Aerospace has achieved a strong level 2 rating and already is satisfying 8 of 17 goals of level 3. Two level 3 key process area goals were fully satisfied : Software Product Engineering and Peer review.

\section{Development of a Systems Engineering Process}

Although the organization had in use ISO-9001 compliant procedures describing the work that systems engineers have to perform, it was decided that a systems engineering process had to be defined in order to integrate, seamlessly, disciplines associated with systems engineering. In 1995, we conducted an internal assessment of our systems engineering practices using the Systems Engineering Capability Maturity Model (SE-CMM) (Bate 1995) and the SE-CMM Appraisal Method (SAM). The objective was to help identify priorities for improvement within the 18 process areas of the SECMM. Three systems engineers and two management staffs answered the SAM questionnaire. Results from the questionnaire were compiled and a maturity level for each process area was computed. After analysis of the results management decided to put a higher priority on the engineering process areas as defined in the SE-CMM. Managers reviewed the current literature and a decision was made to use, as frameworks, the SE-CMM and the Generic Systems Engineering Process (GSEP) developed by the Software Productivity Consortium (SPC 1995). The GSEP has been developed to incorporate most of the practices of the SE-CMM. A working group, composed of 11 systems engineers, software engineers and a representative from quality assurance, was established to define and facilitate the implementation of a systems engineering process. Another objective of the working group is to integrate the current software engineering processes to the systems engineering process. This objective is part of the progress that has to be made to work at SEI level 3 of the CMM for software.

The GSEP document describes, using the IDEF notation (USAF 1981), management and technical activities and also the artifacts produced by each 
activity. The major management activities, as illustrated in figure 4, are: understand context, analyze risk, plan increment development, track increment development and develop system. The major technical activities, as illustrated in figure 5, are: analyze needs, define requirements, define functional architecture, synthesize allocated architecture, evaluate alternatives, validate and verify solution and control technical baseline. Each major activity is broken down in a certain number of smaller activities which are described, individually using the ETVX notation. Our strategy is to define a beta version of the technical activities, then of the management activities, use the beta version on pilot projects and make corrections to both management and technical activities of the process before full deployment.

In addition to defining the process, each member of the working group has a secondary duty. As each step of the beta version of the process is defined, members of the working group were tasked to collect the following information: updates to process descriptions, monitor compliance with the SE-CMM, monitor the interfaces with the software engineering processes, identify process and product measurements, identify roles and responsibilities, define glossary, identify methods, best practices, artifacts, CASE tools, life cycle representations, project templates, estimation guidelines, course material, training resources, lessons-learned, and establish the systems engineering process asset library. Finally, since Oerlikon Aerospace has been certified as an ISO 9001 organization, in 1993, one representative from the quality assurance department monitors our progress in order to make sure that the process being defined is compliant to ISO requirements. Oerlikon Aerospace is planning to perform an independent systems engineering assessment, by the end of 1997 , to measure the progress made and plan a second phase of systems engineering process improvements.

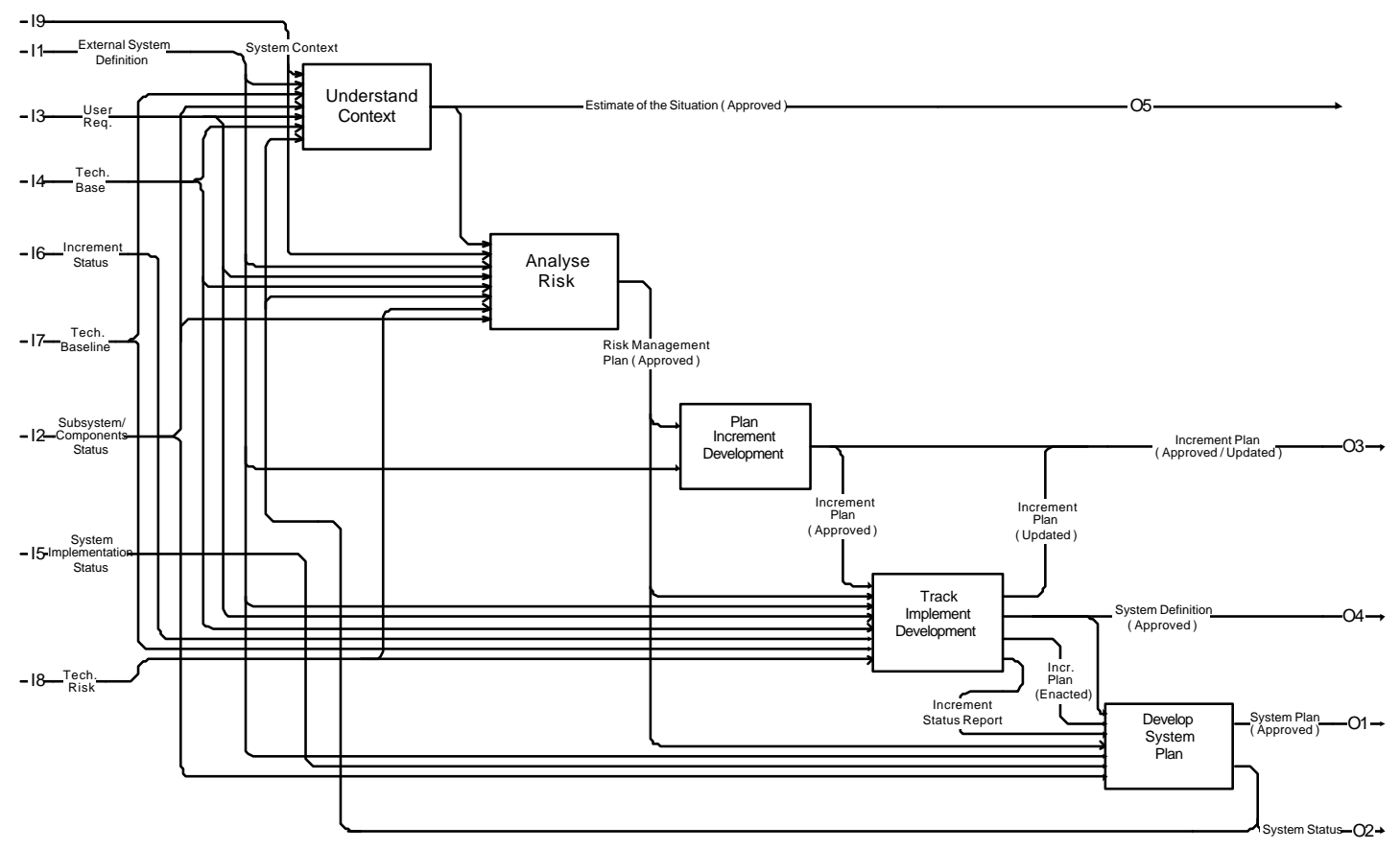

Figure 4: Management Activities of the Systems Engineering Process 


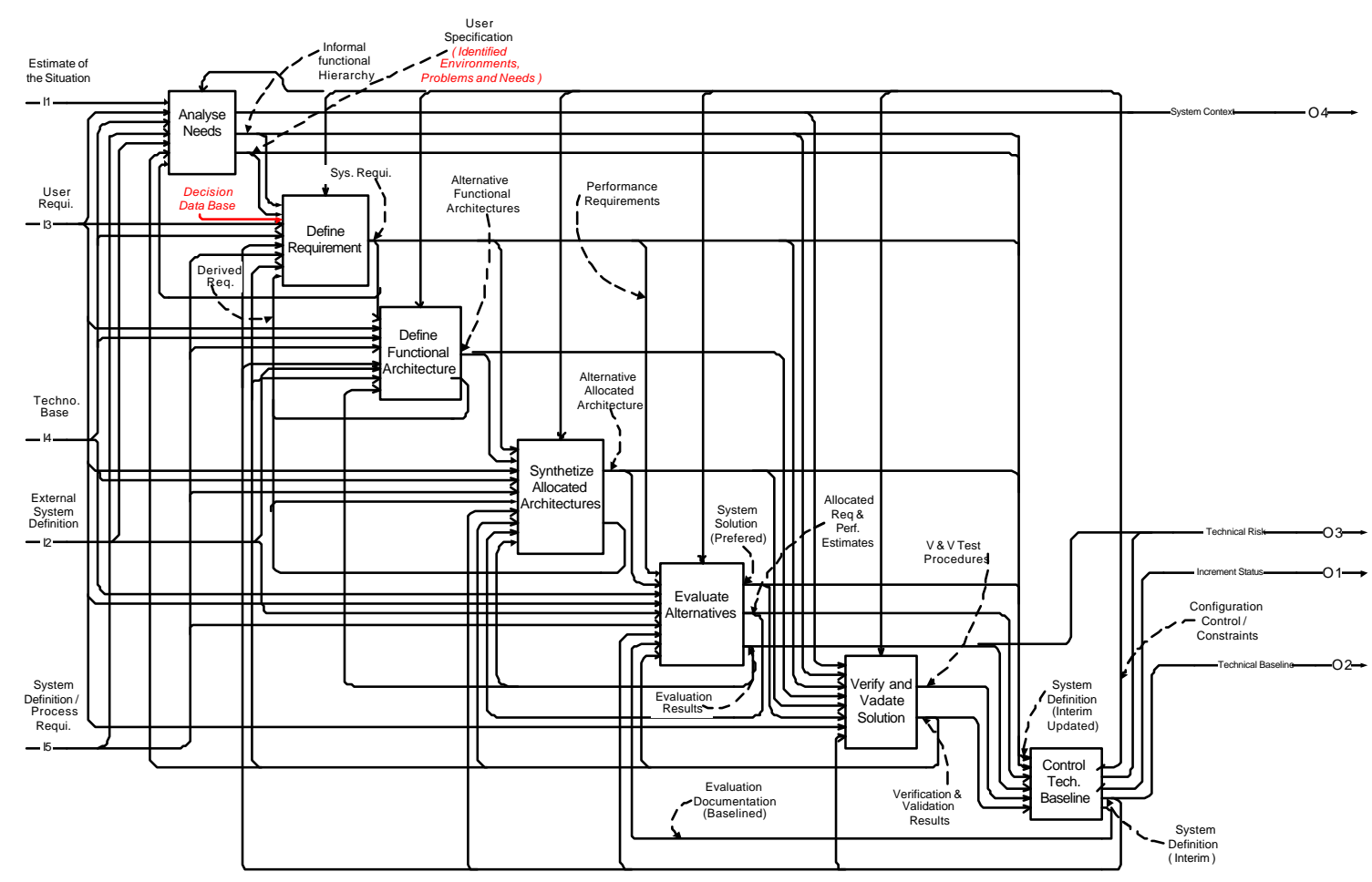

Figure 5: Technical Activities of the Systems Engineering Process

\section{Integration of the Software Engineering Process to the Systems Engineering Process.}

The next step is to integrate the software engineering process to the systems engineering process. We have used, as a framework, a document produced by the SPC entitled: Integrated Systems and Software Engineering Process (ISSEP)(SPC 1996). ISSEP defines a set of management and technical activities and the following interfaces: (1) interfaces between the management and technical activities, (2) interfaces among management activities, (3) interfaces among technical activities and (4) interfaces between the systems and software development processes. Similarly to the GSEP, ISSEP is adaptable and tailorable to a range of applications and project environments. ISSEP describes activities at three different levels: the system level, the Configuration Item(CI) level and the component level. The system level activities are: manage system development, design and verify system, and integrate and test system. At the CI level the activities are: manage CI development, design and verify CI, develop component, and integrate and test CI. The CIs may be decomposed into one or many components. The activities at the component level are: implement component, develop unit test cases, and perform unit testing \& analysis. It is at the component level that software is coded or hardware is manufactured.

The systems engineering process will serve as the background common process framework of all engineering activities e.g. the software engineering activities, the design engineering activities and the logistical engineering activities. For each new project, the project manager, in collaboration with systems and software engineering, will tailor a life cycle and map the management and technical activities adapted to the customer's selected life cycle. Also, links between the systems engineering process and the software engineering process will be identified. Links are typically customer-supplier relationships. As an example, during the development of the Systems Engineering Master Plan (SEMP) estimation data from the Software Development Plan (SDP) will be requested. In this case the customer process is 
systems engineering and the supplier process is software engineering.

Another feature was built in the systems and software processes in order to capture lessons learned. We have defined the software planning and tracking processes such that it is the first process to be initiated in any project and also the last process to be called at the completion of a project. During the planning phase, the project has to estimate the effort required to conduct lessons learned reviews. During the tracking phase, lessons learned reviews are performed in each project. In order to make sure that the lessons are learned by the organization, each lesson is analyzed in order to identify if a process step could be improved (Basili 1994). If this is the case, modifications to the process, methods or guides are made before the project is allowed to exit from the last step of the tracking process.

\section{The Management of Change}

Since the management of change is a key element of a successful process improvement program, a series of actions were planned in order to facilitate the development, the implementation and the adoption of the processes, methods and tools (Laporte, 1993). As an example, to build the sponsorship level, the president attended a one-day executive seminar on process improvement at the SEI, two directors attended a three-day seminar discussing the CMM, process, process assessment and improvement. Also, one member of the SEPG attended two courses at the SEI: managing technological change and consulting skills. Briefing sessions were held and articles were written in each company's newsletter to explain the why, what and how of process assessment and improvement and describing the progress made. Finally, surveys were conducted in order to assess the organization's readiness to such a change in practices. The surveys identified strengths of the organization and potential barriers to the planned improvement program.

Also, in order to get support and commitment for the future implementation of processes, working groups were staffed with representatives from many departments: software engineering, systems engineering, sub-systems engineering, quality assurance, contract management, and configuration management. Each working group was managed like a project. It had a charter, a budget and a schedule. A process owner, i.e. a manager responsible for the definition, implementation and improvement of each process was part of a working group. A member of the SEPG acted as a facilitator in each working group. Therefore, the process owner would focus on the content of a specific software process while the facilitator would focus on the process of developing a specific software engineering process.

\section{Lessons Learned}

It was observed that software and systems engineering process improvement really picked-up momentum when a common focal point was created between management, engineers and customers. Understanding that the real benefit of process improvement lies in improving product quality, reducing time-to-market and cost. Consequently, improving the ability of the organization to better compete. Additionally, a multi-year Process Improvement Plan (PIP) is a very important tool to illustrate the links between project requirements and process development. Essentially the PIP illustrates that the engineering of processes is not a paper exercise but an important infrastructure for the successful accomplishment of projects. Being a multiyear plan, the PIP also shows to practioners the longterm commitment of management to process improvement activities.

It is also very important to carefully select pilot projects and participants to the pilots since these projects will foster adoption of new practices throughout the organization. Also, first time users of a new process will make mistakes. It is therefore mandatory to properly coach the participants and provide them with a "safety net". If participants sense that mistakes will be used to learn and make improvements to the process instead of "pointing fingers", the level of anxiety will be reduced and they will bring forward suggestions instead of "hiding" mistakes.

Managing the human dimension of the process engineering initiative is the component which not only fosters the adoption of change but creates an environment where changes could be introduced at an increasingly greater rate. Members of the engineering organization now realize that managing the "soft stuff" is as important as managing the "hard stuff".

The utilization of models such as the CMM for software and systems engineering is slowly changing 
the culture of the organization from the "Not Invented Here" (NIH) to the "Not Reinvented Here" (NRH) mindset. Practioners see the benefits of reusing someone else's work. They also see that the organization encourage them to look for solutions instead of constantly reinventing the wheel. Engineers are now intensively using the Internet to look for practices developed by other organizations and adapting these practices to the environment of the organization. Practioners attend conferences sponsored by organizations such as the SEI and INCOSE to identify best practices for their utilization in day-to-day activities.

\section{Next Steps}

A training program will be defined. For software engineers, we have identified a career development program developed by the British Computer Society (BCS) (Taylor 1991). This program is currently used by employers, since 1985, mainly in United Kingdom and in other countries. This program is available in North America through DPMA (Data Processing Management Association). The key features of the program are: cyclic and pre-planned and documented programs of training and experience worked out between employer and employee; industry-wide performance standards; evaluation of the completion of these program by independent experienced professionals; registration of completed programs in a standardized Log-Book owned by the employee. The performance standards are based on the BCS's Industry Structure Model (ISM). The ISM defines over eighty detailed job descriptions and up to 10 competence levels, for each job description, ranging from an unskilled entry level to a senior manager or director. Each competence level describes the recommended academic background, the experience and level of skill at entry, tasks and attributes, and training and development required. In addition to the BCS program, the practices described in the CMM level 3 training KPA (Paulk 1993) and in the People CMM (Curtis 1995) will also be used to define the training program (Carpenter 1995) for software engineers. A similar approach will be used for the other engineering disciplines.

Presently most of our process assets are paper documents. As we progress, these documents will be made available on the company local area network. Practioners will have read only access privileges. Only process owners and the process asset librarian will have all read and write privileges.
As we are making progress in institutionalizing systems and software engineering processes and methods, we will be using more CASE tools. Since CASE tools are quite expensive both in acquisition costs and maintenance costs, we cannot afford to make mistakes. But as the organization matures, our requirements for CASE tools will be better defined and the tools selected will better support the execution of the systems and software engineering processes and methods.

As the engineering division moves toward concurrent engineering and integrated product development (IPD), the structure of the organization as well as the performance management process and the reward system will need some adjustments in order to capture the full benefits of these new work practices.

\section{Conclusion}

Our organization has made substantial investments toward the definition implementation and integration of engineering processes, methods and tools. Improvements require significant investments but, both the technical and management activities will allow complex projects to be developed in a disciplined environment. Engineers and managers will be able to perform their activities more effectively and efficiently. The engineering division is slowly moving from the "not invented here" to the "not reinvent here" culture.

\section{References}

Basili, V., Green, S., " Software Process Evolution at the SEL”, IEEE Software, July 1994.

Bate, R., “ A Systems Engineering Capability Maturity Model", version 1.1, Software Engineering Institute, CMU/SEI-95-01, November 1995.

Carpenter, M.B., Hallman, H.,K., "Training Guidelines: Creating a Training Plan for a Software Organization", Software Engineering Institute, CMU/SEI-95-TR-007, September 1995.

Curtis, B., et al, “ People Capability Maturity Model”, Software Engineering Institute, CMU/SEI-95-MM-02, September 1995. 
Fowler, P. Rifkin, S., "Software Engineering Process Group Guide", Software Engineering Institute, Report CMU-SEI-TR-24, September 1990.

Gilb,T., Graham, D., "Software Inspection", Addison Wesley, 1993.

Laporte, C.Y., "Process Improvement and the Management of Change", Proceedings: 4th IEEE Computer Society Workshop on Software Engineering Technology Transfer, Dallas, April 28-29 1993.

Paulk, M. et al, "Capability Maturity Model for Software", Software Engineering Institute, SEI/CMU93-TR-24, 1993.

SPC, "A Tailorable Process for Systems Engineering", Software Productivity Consortium, SPC-94095-CMC, January 1995.

SPC, “ Integrated Systems and Software Engineering Process", Software Productivity Consortium, SPC96001-CMC, May 1996.

SEI, "Relationships Between the Systems Engineering Maturity Model and Other Products, Version 1.0", Software Engineering Institute, CMU/SEI-94-TR-26, Nov. 1995.

STARS, "Army STARS Demonstration Project Experience Report", United States Air Force, Air Force Material Command, Feb. 1995.

Taylor, J.A., “ Training, Career Development and Registration for Safety Critical Software Systems Specialists", IEEE AES Systems Magazine, September 1991.

USAF, "Integrated Computer-Aided Manufacturing Architecture", Function Modeling Manual (IDEF0), United States Air Force, AFWAL-TR-81-4023, 1981.

\section{Biographies.}

Claude Y. Laporte obtained in 1973 a Bachelor in Science from le Collège Militaire Royal de Saint-jean. In 1980, he obtained a MS in physics at Université de Montréal, and in 1986, a MS in Applied Sciences from the Department of Electrical and Computer Engineering at École Polytechnique de Montréal. He was an officer within the Canadian Armed Forces during 25 years and a professor for over 10 years. From 1988 to 1992, he was involved in the implementation of the Applied Software Engineering Centre. He left the Canadian Forces in 1992 at the rank of major. Since then, he has joined Oerlikon Aerospace where he coordinates the development and implementation of software and systems engineering processes, methods and tools. He is the president of the Montréal Software Process Improvement Network (Montréal SPIN). He is also involved in the establishment of a chapter of INCOSE in Montréal.

Nick Papiccio graduated with a Bachelor degree in Administration Sciences in 1980 from le Collège Militaire Royal de Saint-Jean. He has also completed all the courses for the Master in Project Management with the Université du Québec à Montréal. Since 1982, he has been involved in systems and software engineering especially with the Canadian Patrol Frigate Program. He retired from the Canadian navy as a lieutenant-commander specialized in software engineering. Since 1995, he is the manager of software engineering at Oerlikon Aerospace. He is currently involved with the creation of a Center of Excellence in Software and Systems Engineering for Canada. 